\title{
Clinical risk management in anaesthesia
}

\author{
Jonathan Secker Walker, Michael Wilson
}

Health care is a risky business; clinical risk management is a system which helps reduce avoidable risk to patients and staff, which enhances the quality of care for future patients by identifying areas of risk and by changing practice, and which at the same time protects the financial assets of a healthcare institution. Clinical risk management has been defined by Runciman as the cost effective reduction of risk to levels perceived to be acceptable to society. ${ }^{1}$

\section{What are the risks associated with anaesthesia?}

General anaesthesia entails keeping the patient unconscious, providing adequate analgesia, and relaxing the patient's muscles to facilitate surgery. All these processes may, to a greater or lesser degree depending on the depth of anaesthesia, deprive patients of their respiratory reflexes. Hence safeguarding the patient's airway from the mouth to the lungs and maintaining adequate ventilation is a major component of a general anaesthetic procedure.

According to Utting, the commonest reason for anaesthetists in the United Kingdom contacting the Medical Defence Union, comprising $52 \%$ of its reports, was because they had damaged their patient's teeth during anaesthesia. $^{2}$ More recently, Aitkenhead, analysed the 150 claims to the union between 1989 and 1990 and listed the pattern of more serious injuries leading to actual or threatened litigation (table).

Allegations of painful awareness, accounting for about $12 \%$ of this review series, ${ }^{3}$ continue to be an appreciable problem, perhaps because press coverage has alerted patients to its possibility. The incidence of painful awareness has been reported to be of the order of $0.01 \%$ during elective general surgery. ${ }^{4}$ Among 2000 anaesthetic incident reports Osborne et al found 16 cases of awareness, six due to a syringe swap in which the muscle relaxant suxamethonium was given to a conscious patient and three due to low concentrations of volatile agents; in the remaining seven cases no cause was obvious. ${ }^{5}$ Painful awareness is

Department of
Surgery,
Rayne Institute,
University College
London Medical School,
London
Jonathan Secker Walker,
honorary senior lecturer
Royal United Hospital,
Bath BA1 3NG
Michael Wilson,
consultant anaesthetist
Correspondence to:
Dr Secker Walker

Proportion of serious injuries leading to actual or threatened litigation among 150 claims, 1989-90

\begin{tabular}{lr}
\hline & $\%$ \\
\hline Brain or spinal cord damage & $23 \cdot 8$ \\
Death in postoperative period & $17 \cdot 0$ \\
Awareness during general anaesthesia & $12 \cdot 2$ \\
Death during anaesthesia & $11 \cdot 6$ \\
Pain during regional anaesthesia & $7 \cdot 5$ \\
Peripheral nerve damage & $4 \cdot 1$ \\
Fetal death & $1 \cdot 4$ \\
Suxamethonium pains & $1 \cdot 4$ \\
Miscellaneous injuries & $21 \cdot 1$ \\
(fractured ribs, tissued infusions, & \\
pneumothorax and laryngeal damage) & \\
\hline
\end{tabular}

usually accompanied by hypertension and tachycardia, and such signs should alert the anaesthetist to the possibility that the patient is not fully anaesthetised. Such experiences can lead to post traumatic stress syndrome for patients, for whom early recognition and counselling are advisable. Denial by the anaesthetist of the possibility of awareness during the postoperative visit usually makes the situation considerably worse. In a review of five recent legal cases involving plaintiffs complaining of being awake and in pain during some part of the operation settlements for the plaintiff ranged from $£ 15000$ to $£ 100000$. $^{6}$ The commonest causes related to insufficient induction agent (thiopentone), no volatile agent being given, no hyperventilation and low percentages of nitrous oxide, and the error of not checking that the vaporiser is full.

The immediate postoperative period is potentially dangerous for anaesthetised patients: of the deaths and cases of brain damage in Aitkenhead's review no less than $47 \cdot 8 \%$ occurred in the postoperative period. ${ }^{3}$ Cooper et al used collections of critical incidents in anaesthesia to investigate human errors and equipment failure. ${ }^{7}$ They showed that $82 \%$ of preventable incidents involved human error and only $14 \%$ equipment failure. However, the proportion for human error is increased by many breathing system disconnections, which might equally well have been classed as equipment failure. Evidently, poor equipment design was partially involved with many of the human errors. Cooper et al also described the 10 commonest critical incidents, of which $70 \%$ were related to failure to ventilate the lungs with oxygen (box). Webb et al in an analysis of 2000 incidents showed that the five commonest incidents, comprising $40 \%$ of the total, were all related to ventilatory problems, ${ }^{9}$ and the same pattern applied to recovery wards, in which over two thirds of critical incidents related to ventilation of patients. ${ }^{10}$

\section{Commonest critical incidents in anaesthesia}

Breathing circuit disconnection

Inadequate gas flows

Syringe swap

Gas supply problems

Disconnected intravenous line

Malfunction of laryngoscope

Premature extubation

Circuit misconnection

Hypovolaemia

Problem with endotracheal tube

Source: Cooper $e t a l^{8}$ 


\section{Frequency of risks}

Reliable estimates of the frequency of risk are difficult to obtain, since although death is absolute and measurable, those deaths whose cause is considered to be totally or partially due to anaesthesia are often a subject of debate and the arguments based on imperfect information. Furthermore, the numerator is small and there is often uncertainty about the accuracy of the denominator. Therefore the many differing reported rates of mortality and anaesthesia should be accepted with caution. The report of the Confidential Enquiry into Perioperative Deaths (CEPOD), for example, indicates that only three deaths out of nearly half a million were entirely due to anaesthesia whereas anaesthesia was partly implicated in one death in 1300 deaths. ${ }^{11}$

The reported incidence of complications in anaesthesia depends on definitions, classification, and the enthusiasm of the reporters. The risks change from year to year and country to country as anaesthetic practice alters and adapts. Various values for risk have been reported ${ }^{12}{ }^{13}$ and it is probably less than $0.5 \%$. What matters most is the situation in individual hospitals at a particular time.

\section{Reducing risk}

Risk may be reduced by three strategies, as follows.

- Identifying the causes of accidents and errors and developing preventive measures

- Adopting procedures associated with less risk

- Using monitors to give early warning of trouble, thus allowing the anaesthetist to recover the situation before harm befalls the patient.

IDENTIFYING CAUSES OF ACCIDENTS AND ERRORS AND DEVELOPING PREVENTIVE MEASURES

Accidents may be caused by human error, equipment failure, and some kinds of organisational failure.

\section{Human error}

An anaesthetist has to obtain information about the physiological state of the patient and the progress of the anaesthetic from observing the patient, the monitors, and the anaesthetic machine, the information from which is used to make decisions about the anaesthetic. Any required change will necessitate an action, such as adjusting a control, which must be correctly executed to achieve the desired end. Consequently, human errors may occur during the observation (input), decision making, or action (output) stages.

Input and output errors can be minimised by good equipment design. Advances in the design of monitors have eliminated many subjective errors and introduced a range of important measurements not previously available. A new generation of anaesthetic monitors using computer technology can integrate and display physiological information and raise alarms when predetermined limits are transgressed. The overall aim is to provide information that is easily assimilated, thus reducing the risk of mental overload; unfortunately false alarms are still very common with current monitoring equipment. ${ }^{14}$ This usually means repeating the observation or acquiring other confirmatory evidence, or both, ${ }^{15}{ }^{16}$ by direct observation of the patient or from other monitors.

Traditionally, constant vigilance is expected of the anaesthetist, ${ }^{1617}$ yet it is clear that continuously maintaining total alertness and vigilance is not possible, as confirmed by critical incident studies. ${ }^{17}$ Well designed equipment and physiological monitors trigger a return to total vigilance at appropriate times. Critical incident studies also suggest that there may be an advantage in changing anaesthetists during a long procedure. ${ }^{18}$

When making decisions the anaesthetist has to decide not only whether something is wrong but also why. The monitors indicate which vital signs are abnormal, but the anaesthetist must piece the various items of information together and choose a hypothesis that will lead to the correct action. Often the anaesthetist will follow some, perhaps unconscious, mental rule and select the most common explanation that matches the situation. Known as frequency gambling, ${ }^{19}$ this approach usually provides a correct solution, although not always. ${ }^{20}$ Abstract reasoning will be required to solve a novel problem. This knowledge based behaviour is slower and requires more effort. Anaesthetists need to be taught to question their decisions because clinging to false hypotheses or an inappropriate rule is a well known cause of accidents. This dangerous form of "keyhole" thinking ${ }^{19} 2122$ is especially common in particular circumstances, ${ }^{23}$ when disastrous decisions may be adhered to, irrationally and tenaciously, despite conflicting evidence. Anaesthetists need to be aware of this danger and must be prepared to listen to other opinions. The House of Lords recently upheld a conviction for manslaughter on the grounds that it constituted gross negligence (and hence a criminal offence) for an anaesthetist to have failed to recognise a ventilator circuit disconnection which led to a patient's death.

\section{Equipment failure}

Since faulty equipment rarely causes serious accidents $^{212425}$ or critical incidents ${ }^{8926}$ there is the risk of complacency. Disconnections in the breathing systems carrying oxygen and anaesthetic to the patient are frequent and if undetected can cause death. ${ }^{8}{ }^{26-28}$ But latterly, with the increasing use of disposable breathing systems, this incident seems less common. None the less some form of disconnection warning device is essential.

Various national and international standards organisations have taken an important lead in improving equipment safety. ${ }^{27}$ In the United Kingdom the Medical Devices Directorate ${ }^{24}$ has an important role in developing these standards, evaluating equipment, and approving manufacturers, also being responsible for investigating accidents associated with medical devices and issuing hazard notices and safety action bulletins to warn other users. 


\section{Organisational failure}

Hospitals should provide a safe environment for anaesthesia with well designed and equipped anaesthetic, operating, and recovery rooms. The importance of skilled help - operating department assistants or anaesthetic nurses, recovery nurses, and more senior anaesthetic help (when required)-has already been emphasised in many mortality surveys. ${ }^{11} 2529$ Hospital managers require proof that investment in safety is worthwhile; however, as Brahams pointed out, those who plead lack of cash may regret their decision when a case comes before the courts. ${ }^{30}$

Too few appropriate staff, poor departmental organisation, or insensitive management may lead to fatigue, lack of sleep, hunger, frustration, excessive workload, and poor morale, all of which probably decrease performance. ${ }^{16}$ Although experience and common sense support this view, satisfactory experimental evidence is hard to find and in surveys the number of incidents attributed to these factors is few. ${ }^{91126}$

ADOPTING PROCEDURES ASSOCIATED WITH LESS RISK

Whenever possible, adopting techniques that avoid known risks has obvious advantages. For example, the complications of failed intubation (which include death) will not arise if anaesthetic techniques are chosen which do not require tracheal intubation. Furthermore, it is wise to choose techniques that are "fail safe" ${ }^{23}$; a spontaneously breathing patient will survive a disconnection whereas a paralysed patient may die.

MONITORING AND RECOVERY PROCEDURES

When something does go wrong during an anaesthetic a chain of events is initiated which may lead to harm and, in an extreme situation, to cardiac arrest, an event which could be detected by a single monitor (an electrocardiograph). However, investing in several monitors that can detect different stages in the propagation of an incident is more sensible (a disconnected ventilator may be detected, for example, by falls in inspiratory pressure, tidal volume, end tidal partial pressure of carbon dioxide, and oxygen saturation before the electrocardiogram becomes flat). Different types of monitor cover a range of possible incidents. Consequently if an incident is detected early enough harm may be avoided by the speedy implementation of some recovery procedure. For example, Gaba et al discussing techniques to interrupt evolving anaesthetic accidents, pointed out that $93 \%$ of the critical incidents recorded by Cooper et $a l^{8}$ were successfully managed. ${ }^{15}$ Early detection allows more time to initiate recovery procedures and reduces the likelihood of an incident leading to harm. ${ }^{15} 31$ Factors affecting the recovery sequence have been analysed by Galletly and Mushet. ${ }^{32}$

Prompt corrective action may not allow much time for thought and some incidents may occur so rarely that little experience is gained in handling them. Taking the appropriate recovery action is essential because an incorrect response may precipitate another incident, ${ }^{21}$ which may have even more serious consequences. For these reasons there is much to recommend having readily available a set of Anaesthesia Action Plans. ${ }^{33}$ Such a strategy represents a shift to rule based behaviour rather than the slower knowledge based behaviour. Ideally, decisions about emergency procedures should be made in advance, at leisure, with the benefit of collective wisdom, and incorporated into the department's standard operating procedures. Both DeAnda and Gaba ${ }^{20}$ and Schwid and O'Donnell $^{22}$ using an anaesthesia simulator provided a valuable training tool and also insight into the way anaesthetists deal with critical incidents. Proceeding further, Gaba et al have encouraged specific training in crisis management in anaesthesia. ${ }^{34}$

\section{Managing risk}

A risk management programme in anaesthesia should aim at identifying areas of risk before a patient is harmed and it needs to continuously review, and where necessary improve, various aspects of anaesthesia delivery (box).

\begin{tabular}{|l} 
Aspects of delivery of anaesthesia \\
1 Equipment and monitoring policies \\
2 Adverse incident reporting systems \\
3 Medical records \\
4 Communication and informed consent \\
5 Operating theatre procedures \\
6 Supervision of junior staff and locums \\
7 Locums \\
8 Recovery room \\
9 Continuing medical education, maintenance \\
of skills \\
10 Consideration of risks associated with new \\
techniques \\
11 Damage limitation
\end{tabular}

EQUIPMENT AND MONITORING POLICIES Many departments of anaesthesia have agreed policies for purchasing equipment and deciding the appropriate level of monitoring. Conformity of equipment and monitors decreases the risk of junior anaesthetists being confronted with unfamiliar tools in the middle of the night. Furthermore, a sensible budgetary approach is required to ensure regular servicing of the equipment and a rolling replacement programme, which, if not performed, may lead to patient harm or sudden cancellation of operating lists resulting in inconvenience to patients and loss of revenue to the provider. Enlightened trust status may encourage such budget management, which was usually lacking under previous administrations. Aitkenhead estimated that an anaesthetic machine costing $£ 25000$ discounted over a ten year period would add $£ 4$ to the cost of each operation ${ }^{35}$; anaesthetic work stations that include full integral monitoring and computerised record keeping cost twice as much, but even this would be a tiny proportion of an operation's 
total cost. There is increasing evidence to convince managers that compliance with minimum monitoring standards does improve the safety of anaesthesia. ${ }^{36}$ The Australian incident monitoring study of 2000 incidents showed that the role of monitors in aiding patient safety was thoroughly vindicated. ${ }^{37}$ Tinker et al reviewed 1175 anaesthetic related malpractice claims between 1974 and $1988^{38}$ : among the 1097 claims with sufficient information available for the reviewers to make a judgement, $31.5 \%$ of negative outcomes - the worst rated - would have been prevented by additional monitors. Pulse oximetry and capnometry were judged the most useful monitors. Since minimal standards for anaesthesia have been adopted in the United States the cost of malpractice claims against anaesthesiologists has decreased by about two thirds and in the Harvard group of hospitals insurance premiums for anaesthesiologists have fallen by $40 \%$ and are now less than for a urologist or gynaecologist. ${ }^{39}$

A common cause of incidents is failure to understand how to use the equipment. ${ }^{8} 92640$ This is no surprise; one survey disclosed that $48 \%$ of anaesthetists use new equipment without reading the instruction manual. ${ }^{41}$ Some manuals are ignored because they are excessively long and poorly written. Sometimes, because of urgency or other force of circumstance there is no opportunity for training, and it is regrettable that hospitals commonly fail to ensure that sufficient time is devoted to training.

Another common cause of incidents is failure to check equipment before use s $^{264042}$ : between $30 \%$ and $41 \%$ of anaesthetists perform no checks and, of those who do, few follow the guidelines of the Association of Anaesthetists. ${ }^{43}$ Seemingly the risk of serious injury is perceived as being so small that the effort is not seen to be justified, a view strengthened by the knowledge that trivial equipment related incidents are a daily occurrence which are almost always detected and rectified - a very dangerous attitude.

The anaesthetist is held legally responsible for the functioning of the equipment he or she uses and the drugs given. Apart from the checks of the machine and monitors, other danger areas that need special attention are unlabelled syringes, running repairs to equipment (especially components of the airway), drugs drawn up by other staff, and the vaporiser that looks full but is actually empty, which is one cause of painful awareness. All new staff and locums should receive training on the equipment used by the department and should be provided with protocols for equipment checks.

Procedures to ensure that hazard warning notices and safety action bulletins issued by Medical Devices Directorate are received and read by relevant staff are the responsibility of the hospital managers and the clinical director. In a recent survey in southwest England only $66 \%$ of consultant anaesthetists and $33 \%$ of junior anaesthetists were moderately confident that they had seen relevant notices. ${ }^{41}$
ADVERSE INCIDENT REPORTING SYSTEMS

An integral part of any risk management programme is the reporting of adverse incidents since the collection and interpretation of such data allow patterns of particular or repeated events to be identified. A suitable system will facilitate the mapping of the distribution of incidents within the hospital and is described in greater detail by Lindgren et al. ${ }^{43 a}$ Although complete computerised hospital adverse incident reporting systems are still fairly uncommon in the United Kingdom, anaesthetic audit systems have been recording critical incidents and complications in many hospitals for some years. To be of use, serious or repeated incidents must be investigated and recommendations made to reduce the likelihood of recurrence. The Australian incident monitoring study (AIMS) recommends that a non-culpable culture that encourages reporting of critical incidents is essential if the full potential of incident analysis as a means of identifying risk is to be realised and that this should include accepting anonymous reports. ${ }^{44}$ The relation between hospital wide adverse incident reports and critical incident monitoring in anaesthesia needs to be agreed to avoid unnecessary data collection; incidents in which patients may have suffered actual harm should always be reported to the central risk management system.

\section{MEDICAL RECORDS}

The risk of litigation may be reduced by maintaining high quality anaesthetic records. If the plaintiff has been granted legal aid the hospital will have to pay its own costs of a court case even when it wins. In the High Court this may amount to $£ 100000$. Properly kept anaesthetic records will reduce the chance of the expert witness for the plaintiff, when reviewing the notes, alleging that as a matter of probability (without evidence to the contrary) the cause of, say, brain damage was a hypoxic episode and may prevent the case coming to court. Meticulous notes detailing drug doses and vapour concentrations may help to defend against allegations of awareness. ${ }^{44 a}$ The development of modern complete monitoring systems allows continuous printouts of information monitored, with the ability for the anaesthetist to mark drugs and events on the same chart. These printouts provide valuable evidence of exactly what took place at what time, but it is important to note artifacts and add any necessary explanation.

COMMUNICATION AND INFORMED CONSENT Good communication with patients is a crucial part of clinical practice and one of the most effective means of preventing litigation when patients believe that something has gone wrong. Doctors who seem hurried and uninterested are at risk of being sued even if they practice good quality medicine. ${ }^{45}$ For the anaesthetist this communication needs to start with the preoperative visit. Furthermore, patients now expect to give "informed" consent to the procedures carried out. Lord Bridge, considering the case of Mrs Sidaway 
versus the Board of Governors of the Bethlem Royal Hospital in the House of Lords, stated in his judgement, "When specifically questioned by a patient of apparently sound mind about risks involved in a particular treatment proposed, a doctor's duty must, in my opinion, be to answer both truthfully and as fully as the questioner requires." 46 Lord Scarman in a minority judgement in the same case felt that the doctor should be liable "where the risk is such that in the court's view a prudent person in the patient's situation would have regarded it as significant." ${ }^{46}$ There have recently been increasing numbers of legal cases concerning informed consent, many of which have been won by the plaintiff.

In view of the high incidence of complaints to the Medical Defence Union it is prudent to warn patients about the possibility of damage to their teeth, particularly to teeth that are already loose and in patients with capped or crowned teeth. Similarly, if regional analgesia is proposed the possibility of pain or discomfort (accounting for $7.5 \%$ of claims to the Medical Defence Union) should be discussed and the patient reassured about the action the anaesthetist would take. If the patient is clearly unhappy at the prospect and there is no strong contraindication for general anaesthesia it is probably wiser to opt for a general anaesthetic. Consent for the use of suppositories for postoperative analgesia should always be sought from the patient preoperatively. ${ }^{47}$ If general anaesthesia with concurrent regional analgesia is proposed it is important to explain this to the patient (or their parent): a patient expecting general anaesthesia who in addition suffers an inadvertent spinal tap or neurological damage is likely to feel upset and angry. A report of the preoperative visit and the issues discussed should always be made in the patient's notes.

\section{OPERATING THEATRE PROCEDURES}

Each operating theatre should have strict procedures for checking the patient, the intended operation, and the consent form. The operating list should be clearly displayed with the patients' names, hospital numbers, and intended operation. The order of the operating list should be altered only for emergencies and patients should be accompanied by their notes, any relevant radiographs or electrocardiograms, and results of blood tests. Skilled help for the anaesthetist should be available throughout 24 hours. ${ }^{112529}$ Good operating theatre procedures should ensure that trained staff routinely protect patients against injury to eyes, nerves, and skin and from diathermy burns. In addition, training for staff in lifting and handling patients is an important safeguard against back injury, a common cause of staff sickness which may lead staff to sue their employer.

SUPERVISION OF JUNIOR STAFF

Failure to supervise junior anaesthetists is a common factor in anaesthetic accidents. Reports by Lunn and Mushin ${ }^{48}$ and the later CEPOD reports ${ }^{11}{ }^{25}$ indicate that perioperative mortality is to some degree related to the supervision of trainees in anaesthesia, especially in very sick or elderly patients or patients admitted as emergencies. Cooper showed that lack of supervision was the single most commonly associated factor in anaesthetic mishaps ${ }^{7}$ and Gannon that inadequate supervision was a factor in $32 \%$ of anaesthetic deaths. ${ }^{49}$ The CEPOD report of 1987 recommended that a consultant should be responsible for all elective lists. ${ }^{11}$ Medical audit databases can provide useful information as to the degree of supervision and types of cases that juniors are undertaking, which can also be used for their training logbook.

Clinical directors of departments of anaesthesia are responsible for ensuring that the service provided for each operating list is given by appropriately qualified anaesthetists and that junior staff are aware of guidelines and rules, especially when to call for help. A common cause for concern is lack of induction courses for staff (especially locums) joining departments. Training of young anaesthetists should emphasise the value of "safe" anaesthetic practice in reducing risk to the patient and of being alert to the possibility of awareness.

\section{LOCUM COVER}

Locums are commonly involved in medicolegal problems. Often hired in haste to fill gaps in staffing cover, frequently for a weekend, their credentials may not be fully checked. Some doctors remain locums because of difficulty in securing a recognised post and tend to pass from one short term job to another. They may encounter considerable difficulty in keeping their postgraduate training up to date. It is important that the consultant responsible for obtaining locums vets their qualifications and experience, and he or she must make checks with a previous employer. ${ }^{50}$ Too often this task is left to a very junior medical staffing officer. The degree to which junior staff locums may be left unsupervised should be decided by the clinical director and made explicit to the person responsible for drawing up the rota. Special care needs to be taken with locum consultants who will be left without supervision.

\section{RECOVERY ROOMS}

The use of recovery rooms, provided they are appropriately staffed and equipped, should lead to fewer accidents occurring in the immediate postoperative period, and recovery rooms should be available to receive all postoperative patients 24 hours a day. ${ }^{1125}$ The precipitate return of a patient to a surgical ward, where the degree of patient supervision may be much less, owing to inadequate staffing and the consequences of skill mix reviews in the interests of economy, does place sick postoperative patients at risk of complications going unrecognised, and the anaesthetist may be criticised for allowing discharge to the ward too early. High dependency units or the postanaesthetic recovery (PAR) rooms used in many North American hospitals, where patients stay for considerable periods after major surgery before returning to the ward, have 
much to commend them. They have the added advantage of allocation of an anesthetist to the facility, enabling cardiorespiratory instability to be treated and proper pain relief maintained, and in addition, postoperative complications are more likely to be accurately recorded than in the ward.

CONTINUING MEDICAL EDUCATION

The importance of postgraduate education and training has been a feature in published work related to adverse events in anaesthesia. A risk management programme should keep under review the opportunities and funding available to staff for continuing education.

The royal colleges are all developing continuing medical education schemes for consultants, requiring a set number of hours of approved study in order to retain the right to teach. It is not clear, at this point, what sanctions will apply for failure to comply.

The current position as regards the Calman recommendations for staff in training ${ }^{51}$ is also unclear. The proposals for the hours that junior doctors may work; new style training posts, meaning significant reductions in the availability and numbers of junior staff; an official ceiling on the numbers of non-consultant career grades; and a shortage of available potential consultants will all tend to make anaesthetic staffing increasingly difficult to maintain and hamper opportunities for time allowed for junior staff to attend courses for specialist diplomas, in house postgraduate meetings, and training in practical anaesthesia.

The job description and contract of consultants in the National Health Service do not encourage flexibility of interpretation. Accreditation entails demonstrating broad skills across the anaesthetic spectrum. However, after appointment to a consultant post an anaesthetist may be contractually required to cover the same operation lists for years making it difficult to maintain skills in subspecialities which require constant practice, especially in small children, thoracic and vascular surgery, emergency neurosurgery, neonatal care, and cardiac surgery. Many such cases are referred to regional centres but a patient reasonably expects that the anaesthetist is appropriately skilful for their particular condition. Clinical directors bear the responsibility of ensuring that operating sessions are covered by doctors with appropriate specialist competence. Frequently on call work is split into subspeciality rotas such as those for small children, obstetrics, and intensive care. Postgraduate training should be available to consultants to promote their maintenance of necessary experience and skills, including advanced trauma (ATLS) and cardiac life support (ACLS) courses. This may require flexibility in the weekly timetable and, in smaller hospitals, the opportunity to practise in larger postgraduate centres.

EVAI.UATING RISKS ASSOCIATED WITH NEW IECHNIQUES

Anaesthesia has to adapt to changing surgical requirements, and hazards that may be peculiar to a new operation or anaesthetic technique need to be considered. In the early days of laparoscopy patients were occasionally anaesthetised solely with a mask and spontaneous ventilation, with inevitably serious consequences. Laser surgery to the lower respiratory tract to relieve the dyspnoea of bronchial tumour is a procedure potentially fraught with hazard, and laparoscopic cholecystectomy has cardiovascular effects on older patients under general anaesthesia that might not have been expected. ${ }^{52}$ Such procedures need consideration, discussion, and evaluation by senior anaesthetists before a protocol is developed and junior staff left unsupervised.

DAMAGE LIMITATION

Even in the best hospitals accidents will continue to happen, and the organisation needs to develop policy as to how to cope with a patient who has been harmed and who is angry or with the relatives. Denial and secrecy usually lead to an increasingly vindictive victim whereas honesty, discussion, and offers of support may defuse the situation before lawyers become involved.

Patients who have suffered anaesthetic awareness need counselling and understanding, and it is essential that nurses in whom the patient may confide always inform the anaesthetist involved as soon as possible. ${ }^{4 t a}$

Admitting to an accident need not automatically include admission of any negligence. Patients are often very anxious that their bad experience will not be suffered by others and seek reassurance that the hospital has learnt from the event. Early support for the patient by staff mature enough to deal with the situation is important, as is support for the doctor or nurse, who usually feels very deeply about the accident and whose feelings are all too often ignored.

A recent study suggests that many senior doctors suffer high levels of stress, both anxiety and depression. ${ }^{53}$ Other studies have found similar problems in junior doctors. ${ }^{54}{ }^{55}$ Psychological ill health often leads to excessive alcohol use or drug dependency. These are conditions which are dangerous for patients in any doctor but can be quickly lethal in an anaesthetist. To turn a blind eye on a troubled colleague does no one any good. There are procedures to help sick doctors before patients are harmed, in particular the three wise men procedure, ${ }^{50}$ the mechanism of which should be clearly understood by all medical and senior nursing staff. Additionally, professional help for a sick anaesthetist can be provided by the confidential Counselling Service for Anaesthetists based at the Association of Anaesthetist's headquarters.

To most anaesthetists the issues discussed in this chapter will be familiar, and yet in the hurly-burly of modern hospital life it is often difficult for the clinical director and his or her colleagues to find the time to review risk factors regularly and remind and educate new and current staff about methods to reduce avoidable risk. Such regular review perhaps three monthly - might become the 
responsibility of a particular consultant and could, like clinical audit, become a part of regular postgraduate training programmes in order to promote a continuing improvement in patient safety.

1 Runciman WB. Risk assessment in the formulation of anaesthesia safety standards. Eur $\mathcal{f}$ Anaesthesio 1993;10(suppl 7):26-32.

2 Utting JE. Pitfalls in anaesthetic practice. $\mathrm{Br} \mathcal{F}$ Anaesth 1987;59:877-90.

3 Aitkenhead AR. Risk management in anaesthesia. fournal of the Medical Defence Union 1991;4:86-90.

4 Jones JG. Memory of intraoperative events. $B M \mathcal{F}$ 1994;309:967-8

5 Osborne GA, Webb RK, Runciman WB. Patient awarenes during anaesthesia: an analysis of 2000 incident reports. Anaesth Intensive Care 1993;21:653-4.

6 Payne JP. Awareness and its medicolegal implications. $\mathrm{Br} \mathcal{F}$ Anaesth 1994;73:38-45.

7 Cooper JB, Newbower RS, Kitz RJ. An analysis of majo errors and equipment failure in anesthesia management: considerations for prevention and detection. Anesthesiology 1984;60:34-42.

8 Cooper JB, Newbower RS, Long CD, et al. Preventable anesthesia mishaps. Anesthesiology 1978;49:399-406.

9 Webb RK, Van Der Walt JH, Runciman WB, et al. Which monitor? An analysis of 2000 incident reports. Anaesth Intensive Care 1993;21:529-42.

10 Van Der Walt JH, Webb RK, Osborne GA, et al. Recovery room incidents in the first 2000 incident reports. Anaesth Intensive Care 1993;21:650-2.

11 Buck N, Devlin HB, Lunn JN. Report of a confidential enquiry into perioperative deaths (CEPOD). London: Nuffield Provincial Hospitals Trust/King's Fund, 1987.

12 Tiret L, Desmonts J-M, Hatton F, et al. Complication associated with anaesthesia - a prospective survey in France. Canadian Anaesthetists Society fournal 1986;33. 336-44.

13 Cohen MH, Duncan PG, Pope WDB, et al. A survey of 112,000 anaesthetics at one teaching hospital. Canadian Anaesthetists Society fournal 1986;33:22-31.

14 McIntyre JWR. Alarms in the operating room. Can $f$ Anaesth 1991;38:951-3.

15 Gaba DM, Maxwell M, DeAnda A. Anesthetic mishaps: breaking the chain of accident evolution. Anesthesiology 1987;66:670-6.

16 Gaba DM. Human error in anesthetic mishaps. In Anesthesiol Clin 1989;27:137-47.

17 Newbower RS, Cooper JB, Long CD. Failure analysis - the human element. In: Gravenstein JS, Newbower RS, Ream $\mathrm{AK}$, et al, eds. Essential non-invasive monitoring in anesthesia. New York: Grune and Stratton, 1980:269-82.

18 Cooper. JB, Long CD, Newbower RS, et al. Critical incidents associated with intraoperative exchanges of incidents associated westhesiology 1982;36:456-61.

19 Reason J. Human error. New York: Cambridge University Press, 1990.

20 DeAnda A, Gaba DM. Role of experience in the response to simulated critical incidents. Anesth Analg 1991;72. 308-15.

21 DeAnda A, Gaba DM. Unplanned incidents during comprehensive anesthesia simulation. Anesth Analg 1990;71:77-82.

22 Schwid HA, O'Donnell D. Anesthesiologist's managemen of simulated critical incidents. Anesthesiology 1992;76: 495-501.

23 Hawkins FH. Human factors in flight. Aldershot: Gower Technical Press, 1987.

24 Barton A. 'Alarm signals' over warning signs? Anaesthesia 1991:46:809.

25 Campling EA, Devlin HB, Hoile RW, et al. Report of the national confidential enquiry into perioperative deaths 1990. London: Nuffield Provincial Hospitals Trust/King's Fund, 1987.

26 Craig J, Wilson ME. A study of anaesthetic misadventures. Anaesth 1981;36:933-6.

27 Thompson PW. Safer design of anaesthetic machines. $\mathrm{Br} F$ Anaesth 1987;59:913.
28 Currie M. A prospective survey of anaesthetic critical events in a teaching hospital. Anaesth Intensive Care 1989; 17:403-11.

29 Department of Health, Welsh Office, Scottish Home and Health Department, and DHSS, Northern Ireland. Report on confidential enquiries into maternal deaths in the United Kingdom 1985-1987. London: HMSO, 1991.

30 Brahams D. Anaesthesia and the law. Monitoring. Anaesthesia 1989;44:606-7.

31 Schreiber P, Schreiber J. Anesthesia system risk analysis and risk reduction. Telford, Penssylvania: Drager, 1987.

32 Galletly DC, Mushet NN. Anaesthesia system errors. Anaesth Intensive Care 1991;19:66-73.

33 Eaton JM, Fielden JM, Wilson ME. Anaesthesia action plans. 2nd ed. Maidenhead, Berkshire: Abbott Laboratories, 1994.

34 Gaba DM, Howard SK, Fish KJ, et al. Anesthesia crisis resource management training. Anesthesiology 1991;75: A1062.

35 Aitkenhead AR. Risk management in anaesthesia. Healthcare Risk Management Bulletin 1992;2:4-5.

36 Eickhorn JH. Prevention of intraoperative anesthesia accidents and related severe injury through safety monitoring. Anesthesiology 1989;70:572-7.

37 Morgan CA, Webb RK, Cockings JA, et al. Cardiac arrest an analysis of 2000 incident reports. Anaesth Intensive Care 1993;21:626-37.

38 Tinker JH, Dull DL, Caplan RA, et al. Review of 1175 anesthesia related malpractice claims between 1974 and 1988. Anesthesiology 1989;71:541-6.

39 Taylor TH, Goldhill DR. Standards and audit. In: Standards of care in anaesthesia. Oxford: Butterworth-Heinemann, 1992:170.

40 Kumar V, Barcellos WA, Mehta MP, et al An analysis of critical incidents in a teaching department for quality ssurance. A survey of mishaps during anaesthesia. assurance. A survey of mish

41 Weir PM, Wilson ME. Are you getting the message? A look at the communication between the Department of Health, manufacturers and anaesthetists. Anaesthesia 1991;46: $845-8$.

42 Chopra V, Bovill JG, Spierdijk J, et al. Reported significan observations during anaesthesia: a prospective analysi over an 18 month period. Br f Anaesth 1992;68:13-7.

43 Mayor AH, Eaton JM. Anaesthetic machine checking practices: a survey. Anaesthesia 1992;47:866-8.

43a Lingren O, Secker Walker J. Instant reporting systems early warning for the prevention and control of clinical negligence. In: Vincent C, ed. Clinical risk management. London: BMJ (in press)

44 Runciman WB, Sellen A, Webb RK, et al. Errors, incidents and accidents in anaesthetic practice. Anaesth Intensive and accidents in anaesth

44a Aitkenhead AR. Awareness during anaesthesia: what the patient should be told. Anaesthesia 1990;45:351-2.

45 Hickson G, Clayton EW, Entman SS, et al. Obstetricians' prior malpractice experience and patients' satisfaction with care. $\mathcal{F} A M A$ 1994;272:1583-7.

46 Sidaway $v$ Board of Governors of the Bethlem Royal and the Maudsley Hospital [1985] 2 WLR 480.

47 Mitchell J. A fundamental problem of consent. $B M 9$ 1995;310:43-6.

48 Lunn JN, Mushin WW. Mortality associated with anaesthesia. London: Nuffield Provincial Hospitals Trust, 1982.

49 Gannon K. Mortality associated with anaesthesia. Anaesthesia 1991;46:962-6.

50 Atkinson RS. The problem of the unsafe anaesthetist. $\mathrm{Br} \mathcal{F}$ Anaesth 1994;73:29-30

51 Department of Health. Hospital doctors: training for the future. Report of the Working Group on Specialist Medical Training. London: HMSO, 1993.

52 Bromley LM. Does minimal access cholecystectomy require simple anaesthesia? Clinical Risk 1995;1:18-21.

53 Caplan RP. Stress, anxiety, and depression in hospital consultants, general practitioners, and senior health service managers. BMF 1994;309:1261-3.

54 Valko RJ, Clayton PJ. Depression in the internship. Diseases of Nervous System 1975;36:26-9.

55 Reuben DB. Depressive symptoms in medical house officers. Effects of level of training and work rotation. Arch Intern Med 1985;145:286-8.

56 Department of Health. Prevention of harm to patients resulting from physical or mental disability of hospital or community medical or dental staff. London: $\mathrm{DoH}, 1982$. (HC982)13.) 